\title{
Abordagem dos Temas Alimentação e Nutrição no Material Didático do Ensino Fundamental: interface com segurança alimentar e nutricional e parâmetros curriculares nacionais Approach to Food and Nutrition issues in Teaching Materials in Elementary School: interface with food and nutritional security and national curriculum parameters
}

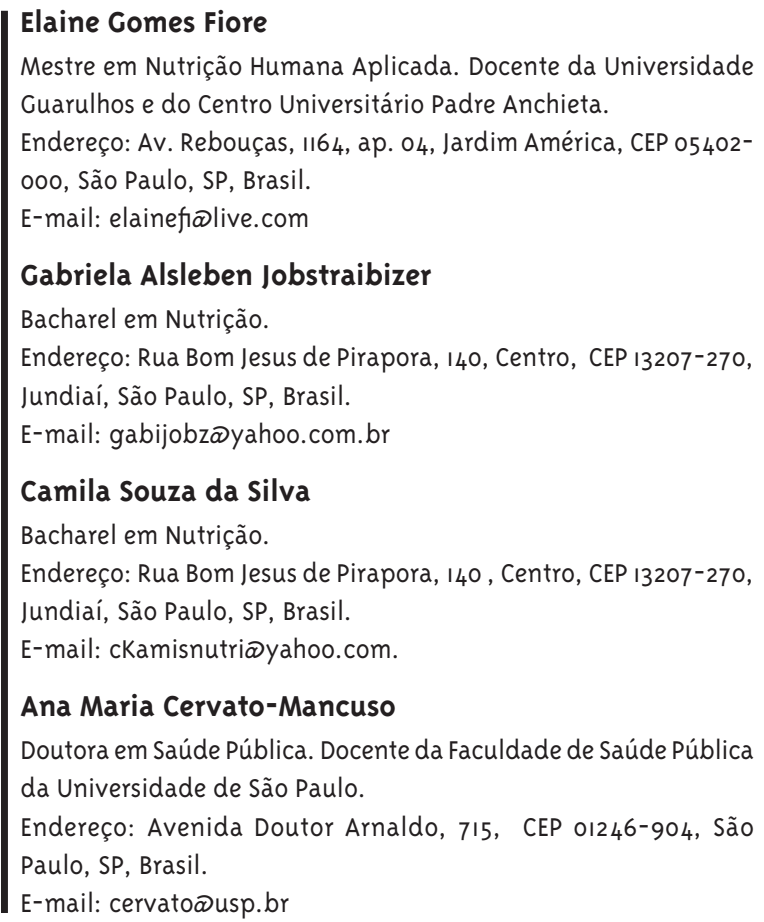

E-mail: cervato®usp.br

\section{Resumo}

A Segurança Alimentar e Nutricional (SAN) deve ser assegurada a todos. A escola é ambiente propício à formação de hábitos saudáveis e à construção de cidadania. Os Parâmetros Curriculares Nacionais (PCNs) orientam a promoção de concepções de saúde de modo transversal no currículo escolar. Este estudo teve como objetivo identificar e analisar a abordagem dos temas alimentação e nutrição no material didático do ensino fundamental e sua interface com o conceito de SAN e com os PCNs. Foi realizada pesquisa documental mediante o material didático de $5^{\text {a }}$ a $8^{\text {a }}$ séries do ensino fundamental da rede pública do Estado de São Paulo. A presença difusa do tema alimentação e nutrição na maioria das disciplinas, por todos os bimestres, nas quatro séries, traz à tona a interdisciplinaridade em saúde. Verificou-se que os PCNs estão relacionados ao conceito de SAN nos seus diversos aspectos e que a maioria das disciplinas contém temas que abordam esta relação. $\mathrm{Na}$ interface entre os temas, destaca-se a promoção da saúde e a produção dos alimentos. A metodologia utilizada no material didático apresenta o tema, mas não o conteúdo correlato, o que impossibilitou a análise de sua adequação. Conclui-se que existe a abordagem dos temas relacionados à alimentação e nutrição no material didático, alguns de forma inconsistente, e cabe aos educadores a seleção do conteúdo e da estratégia adequada, além de sua constante atualização, o que está sendo proposto 
pelo Estado, mas não está ao alcance de todos os profissionais e, portanto, ainda depende da iniciativa de cada docente.

Palavras-chave: Alimentação; Nutrição; Material didático.

\section{Abstract}

Food and Nutrition Security (FNS) must be ensured to everybody. The school environment is favorable to the formation of healthy habits and citizenship. The National Curriculum Parameters (PCNs) guide the promotion of health concepts in a transversal way in the school curriculum. This study aimed to identify and analyze the approach used for food and nutrition themes in Fundamental Education's teaching material and its interface with the concept of FNS and the PCNs. Documental research was conducted on the teaching material from $5^{\text {th }}$ to 8 th grades of Fundamental Education in Public School of the state of São Paulo. The diffuse presence of food and nutrition themes was found in most disciplines in all bimesters in the four series, which shows the interdisciplinarity in health. It was found that the PCNs are related to the concept of SAN in its various aspects and that most subjects include topics that approach this relationship. In the correlation between themes, there is emphasis to health promotion and food production. The methodology used in the teaching material presents the theme, but not the correspondent content, what made the analysis of its suitability impossible. We conclude that there is the approach of the issues related to food and nutrition in the teaching material, some of them in an inconsistent way; it is the educators' task to select the contents and the appropriate strategy, doing an effort of constant update. This isbeing proposed by the State, however it is not accessible to all professionals and therefore still depends on the initiative of each teacher.

Keywords: Food; Nutrition; Teaching Materials. 


\section{Introdução}

A alimentação, como atividade humana, supera o plano biológico, ocorrendo na dinâmica entre o alimento e o corpo (natureza e natureza humana, respectivamente) e é, por isso, uma construção cultural e simbólica com diferentes perfis de consumo compartilhados em cada sociedade, levando a expectativas e valores em torno desse processo (Valente, 2003; Burlandy, 2007). Por outro lado, ela também pode ser entendida como um direito das pessoas.

A alimentação, como um direito humano fundamental, foi primeiramente prevista na Declaração Universal dos Direitos Humanos (ONU, 1948) e, posteriormente, em vários outros documentos internacionais e nacionais.

Em 1992, o Brasil assumiu o compromisso de garantir o direito humano à alimentação, tornando-se signatário do Pacto Internacional dos Direitos Econômicos, Sociais e Culturais, adotado pela Resolução n2.20o-A (XXI) da Assembleia Geral das Nações Unidas, de 16 de dezembro de 1966 (Brasil, 1992).

A realização deste direito de forma adequada resulta no estabelecimento do conceito de segurança alimentar e nutricional para a criação da Lei Orgânica de SAN (no 11.346/o6) que define:

A segurança alimentar e nutricional consiste na realização do direito de todos ao acesso regular e permanente a alimentos de qualidade, em quantidade suficiente, sem comprometer o acesso a outras necessidades essenciais, tendo como base práticas alimentares promotoras de saúde que respeitem a diversidade cultural e sejam ambiental, cultural, econômica e socialmente sustentáveis (Brasil, 2006a, p.1)

Uma contribuição trazida pela referida lei foi a instituição do Sistema Nacional de Segurança Alimentar e Nutricional (SISAN), priorizando assegurar à população o direito humano à alimentação adequada (Brasil, 2006a).

Recentemente, em 2010, o direito à alimentação foi mais uma vez reconhecido no País, com a inclusão no artigo 6ํำ da Constituição Federal do Brasil (Brasil, 2010a), como um direito social fundamental do homem:
Art. 6o "São direitos sociais a educação, a saúde, a alimentação, o trabalho, a moradia, o lazer, a segurança, a previdência social, a proteção à maternidade e à infância, a assistência aos desamparados, na forma desta Constituição". (grifo nosso).

Em agosto de 2010 foi assinado, pelo presidente da República, o decreto que instituiu a Política Nacional de Segurança Alimentar e Nutricional (Brasil, 2010b), cujo documento define a forma de gestão, o financiamento, a avaliação e o controle social na busca de assegurar o Direito Humano à Alimentação Adequada.

É possível verificar preocupação do poder público criando leis e normas para regulamentar esse direito e, neste sentido, cumpre observar que essa preocupação está fundamentada em uma realidade na qual a população está sob o risco de não ter esse direito garantido.

Ressalta-se que as preferências alimentares desempenham importante papel na determinação da seleção de alimentos e, portanto, na garantia da alimentação adequada (Fiates e col., 2006). Além disso, muitas das características ou dos hábitos referentes ao estilo de vida do adulto são adquiridos e/ou consolidados na infância e na adolescência (Priore e Franceschini, 2007; Pedrinola, 2002).

O período escolar, para o Ministério da Saúde, é entendido como fundamental para trabalhar a promoção de saúde, pois a população atendida pelo setor educacional vive momentos de criação e revisão de hábitos e atitudes (Ministério da Saúde, 2002).

Apoiada na Lei Federal no 9.394, de 20 de dezembro de 1996 - Lei de Diretrizes e Bases da Educação Nacional, a Secretaria de Educação Fundamental do Ministério da Educação e do Desporto elaborou uma série de documentos como referencial curricular nacional para o ensino fundamental. Esta série, nominada de Parâmetros Curriculares Nacionais (PCNs), procura oferecer às Secretarias de Educação, escolas e demais instituições ou pessoas interessadas em educação, uma proposta de reorientação curricular com princípios e metas do projeto educacional. Dentro destes, há a orientação em promover concepções de saúde de modo transversal no currículo escolar (Brasil, 1998). Isto significa que o tema saúde deverá ser incorporado às áreas ou disciplinas já existentes, organizando o trabalho do equipamento educacional. 
A Portaria Interministerial nํㅜ․o10, de 8 de maio de 2006, instituiu as diretrizes para a Promoção da Alimentação Saudável no ambiente escolar propondo ações a serem realizadas neste, pois considera a escola como ambiente propício à formação de hábitos saudáveis e à construção de cidadania (Brasil, 2006b). Esta portaria ratifica a intervenção pública na questão alimentar dos escolares, dado que o Programa Nacional de Alimentação Escolar (PNAE) é o programa social mais antigo no País na área de Segurança Alimentar, tendo seu início focado na garantia do acesso à alimentação (Santos, 2007).

Recentemente, com a publicação da Lei ${ }^{0}$ 11.947, de 16 de junho de 2009, foram definidas as diretrizes da alimentação escolar, dentre as quais está a inclusão da educação alimentar e nutricional que perpasse o currículo escolar, sendo sua promoção de competência dos Estados, do Distrito Federal e dos Municípios, no âmbito de suas respectivas jurisdições administrativas. Para isto, deve haver atuação conjunta dos profissionais de educação e do nutricionista (Brasil, 2009).

Considerando a importância da alimentação na promoção da saúde de crianças e adolescentes e, consequentemente, no estado de saúde na vida adulta, o respaldo legal que o Direto Humano à Alimentação Adequada vem ganhando, a importância do processo de aprendizagem para adolescentes, bem como o questionamento da forma pela qual a alimentação é abordada na escola, justifica-se o presente estudo, cujo objetivo é identificar a abordagem dos temas alimentação e nutrição presentes no material didático do ensino fundamental e sua interface com o conceito de SAN e com os PCNs.

\section{Metodologia}

Trata-se de pesquisa documental referente ao material utilizado de quinta a oitava séries do ensino fundamental das escolas públicas do Estado de São Paulo, realizada durante 2009 e 2010.

\section{Material educativo consultado}

Por meio de um projeto que propõe um currículo para os níveis de Ensino Fundamental II e Médio, a Secretaria de Educação do Estado de São Paulo elaborou, a partir de amplo levantamento do acervo documental e técnico pedagógico existente, uma série de documentos dirigidos a professores e alunos, são os Cadernos do Professor e do Aluno (São Paulo, 2008).

O material foi organizado em Cadernos do Professor e Cadernos do Aluno por bimestre (quatro bimestres) e por disciplina, sendo elas: Arte, Ciências, Geografia, História, Língua Estrangeira Moderna (Inglês), Língua Portuguesa e Matemática. Desta forma, cada série conta com oito cadernos por disciplina. Para a de Educação Física, o Caderno do Aluno foi feito em volume único, para os dois primeiros bimestres em todas as séries.

O material para a pesquisa documental foi doado pela diretoria de um município do Estado de São Paulo e região. Foram disponibilizados os seguintes volumes: os quatro exemplares dos Cadernos do Professor bimestrais representados pelos volumes 1, 2, 3 e 4, das quatro séries ( $5^{\mathrm{a}}, 6^{\underline{a}}, 7^{\mathrm{a}}$ e $8^{\mathrm{a}}$ séries), das disciplinas: Ciências, Educação Física, Geografia, História, Inglês, Língua Portuguesa e Matemática. Com relação à disciplina de Arte, não foram obtidos o quarto e o terceiro bimestres da quinta e sétima séries, respectivamente. Totalizaram, portanto, 126 volumes.

Quanto aos Cadernos do Aluno, foi obtido menor número de exemplares, totalizando 63 dos 92 volumes disponíveis, sendo que os volumes de número 4 (referentes ao quarto bimestre) ainda não haviam sido distribuídos pela Secretaria Estadual de Educação na época do início da pesquisa e coleta do material.

\section{Dinâmica para análise}

Para analisar o material educativo sobre a abordagem dos temas alimentação e nutrição, tendo como referencial teórico os PCNs e o conceito de SAN, identificaram-se os conteúdos, as disciplinas e as séries.

Os PCNs caracterizam a Educação para a Saúde como um tema transversal do currículo. Entre os conteúdos abordados pelo referido tema transversal dos PCNs, foram destacados os relacionados à alimentação e nutrição, a saber:

- Higiene e alimentação: água para o consumo humano, processos de produção e manuseio de alimentos; 
- Finalidades de alimentação: necessidades corporais, socioculturais e emocionais;

- Estudo do processo completo de nutrição: ingestão, digestão, absorção, anabolismo, catabolismo e excreção;

- Reconstituição do caminho seguido pelos alimentos desde a sua produção até o consumidor: trabalho humano envolvido, utilização de aditivos e agrotóxicos e seus efeitos sobre a saúde dos produtores e consumidores;

- Hábitos alimentares: geração artificial de "necessidades" pela mídia e os efeitos da publicidade no incentivo ao consumo de produtos energéticos, vitaminas e alimentos industrializados;

- Ocorrência simultânea de obesidade e carências nutricionais: consumo de medicamentos emagrecedores, uso excessivo de açúcar na dieta, fator de risco para doenças crônico-degenerativas.

Com a finalidade de relacionar os itens acima descritos ao amplo conceito de SAN, disposto na Lei n-11.346/o6 (Brasil, 2006a), foram identificados os seguintes aspectos como componentes da construção do referido conceito:

- Acesso aos alimentos;

- Utilização sustentável dos recursos;

- Produção de conhecimentos e acesso à informação;

- Qualidade tecnológica;

- Qualidade nutricional;

- Qualidade biológica e sanitária;

- Promoção da saúde.
Selecionaram-se todos os conteúdos de cada caderno que diziam respeito aos itens que compõem o conceito de SAN e os contemplados nos PCNs; em seguida, procedeu-se ao "cruzamento dos dados" para identificar quais itens tinham interface, por intermédio do conteúdo abordado.

A partir desta análise foram identificadas as disciplinas e as séries que abordaram os itens acima citados.

A leitura dos referidos temas presentes no material didático foi realizada de maneira a analisar a qualidade das informações e conceitos transmitidos, segundo sua concordância com os conceitos científicos presentes em livros técnicos e publicações especializadas. Por meio da leitura, também foram identificadas as estratégias propostas pelo material analisado.

\section{Resultados}

O Quadro 1 mostra a distribuição das disciplinas em que foram encontrados os temas pesquisados por séries e bimestres. Verificou-se que a disciplina de Matemática é aquela que menos apresenta em sua proposta de conteúdo os temas relacionados à alimentação e nutrição, seguida pelas disciplinas de Inglês e de Educação Física. Ciências, Geografia e História, por outro lado, são as disciplinas que mais apresentam o tema. Além disso, é possível perceber que durante cada série, o tema alimentação e nutrição é abordado ao longo de todos os bimestres. Entretanto, a oitava série tem menor prevalência dos temas citados.

\section{Quadro I - Distribuição dos temas relacionados à alimentação e nutrição no material didático da quinta a oitava séries do ensino fundamental do Estado, segundo séries e disciplinas. São Paulo, 2009}

\begin{tabular}{|c|c|c|c|c|c|c|c|c|c|c|c|c|c|c|c|c|}
\hline \multirow{2}{*}{ Disciplinas } & \multicolumn{4}{|c|}{$5^{\text {a }}$ série } & \multicolumn{4}{|c|}{$6^{\mathrm{a}}$ série } & \multicolumn{4}{|c|}{$7^{\mathrm{a}}$ série } & \multicolumn{4}{|c|}{$8^{a}$ série } \\
\hline & $1^{\circ}$ bim. & $2^{\circ}$ bim. & $3^{\circ} \mathrm{bim}$ & $4^{\circ} \mathrm{bim}$. & $1^{\circ}$ bim. & $2^{\circ} \mathrm{bim}$ & $3^{\circ} \mathrm{bim}$. & $4^{\circ} \mathrm{bim}$ & $1^{\circ}$ bim. & $2^{\circ} \mathrm{bim}$ & $3^{\circ} \mathrm{bim}$ & $4^{\circ} \mathrm{bim}$. & $I^{\circ} \mathrm{bim}$. & $2^{\circ} \mathrm{bim}$. & $3^{\circ} \mathrm{bim}$. & $4^{\circ} \mathrm{bim}$. \\
\hline Ciências & & & & & & & & & & & & & & & & \\
\hline Ed. Física & & & & & & & & & & & & & & & & \\
\hline Geografia & & & & & & & & & & & & & & & & \\
\hline História & & & & & & & & & & & & & & & & \\
\hline Inglês & & & & & & & & & & & & & & & & \\
\hline L. Portuguesa & & & & & & & & & & & & & & & & \\
\hline Matemática & & & & & & & & & & & & & & & & \\
\hline
\end{tabular}

Interface entre séries e disciplinas 
Os itens dos documentos analisados presentes nos PCNs e no conceito de SAN estão apresentados no Quadro 2. Verifica-se que das 70 possibilidades de interface, foram identificadas 21 , sendo que todos os temas de cada aspecto (PCN ou SAN) estavam presentes nos documentos. É importante destacar que alguns temas dos PCNs fizeram interface com mais de um tema de SAN.

\section{Quadro 2 - Interface entre os itens que compõem o conceito de SAN e os contemplados nos PCNs do material didático da quinta à oitava séries do ensino fundamental do Estado. São Paulo, 2009}

\begin{tabular}{|c|c|c|c|c|c|c|c|c|}
\hline \multirow{2}{*}{ PCNs } & & \multicolumn{7}{|c|}{ SAN } \\
\hline & & Acesso & $\begin{array}{l}\text { Utilização } \\
\text { sustentável } \\
\text { de recursos }\end{array}$ & $\begin{array}{l}\text { Produção de } \\
\text { conhecimentos } \\
\text { e acesso à } \\
\text { informação }\end{array}$ & $\begin{array}{l}\text { Qualidade } \\
\text { tecnológica }\end{array}$ & $\begin{array}{l}\text { Qualidade } \\
\text { nutricional }\end{array}$ & $\begin{array}{l}\text { Qualidade } \\
\text { biológica e } \\
\text { sanitária }\end{array}$ & $\begin{array}{l}\text { Promoção } \\
\text { da saúde }\end{array}$ \\
\hline \multicolumn{9}{|c|}{ Higiene de água e alimentos } \\
\hline \multirow{3}{*}{$\begin{array}{l}\text { Finalidades } \\
\text { da } \\
\text { Alimentação }\end{array}$} & $\begin{array}{l}\text { Necessidades } \\
\text { socioculturais }\end{array}$ & & & & & & & \\
\hline & $\begin{array}{l}\text { Necessidades } \\
\text { corporais }\end{array}$ & & & & & & & \\
\hline & $\begin{array}{l}\text { Necessidades } \\
\text { emocionais }\end{array}$ & & & & & & & \\
\hline \multicolumn{9}{|c|}{ Processo completo de nutrição } \\
\hline \multirow{3}{*}{$\begin{array}{l}\text { Caminho dos } \\
\text { alimentos da } \\
\text { produção ao } \\
\text { consumidor }\end{array}$} & $\begin{array}{l}\text { Segurança do } \\
\text { consumidor } \\
\text { (aditivos e } \\
\text { agrotóxicos) }\end{array}$ & & & & & & & \\
\hline & $\begin{array}{l}\text { Segurança } \\
\text { do produtor } \\
\text { (aditivos e } \\
\text { agrotóxicos) }\end{array}$ & & & & & & & \\
\hline & Outros & & & & & & & \\
\hline \multicolumn{9}{|c|}{ Hábitos alimentares } \\
\hline $\begin{array}{l}\text { Obesidade e c } \\
\text { nutricionais }\end{array}$ & rências & & & & & & & \\
\hline
\end{tabular}

$\square$ Interface entre os itens

Verificou-se que existe uma diversidade de temas referentes à alimentação e nutrição relacionados ao conceito de SAN e contemplados pelos PCNs em todas as séries e disciplinas. Destaca-se, neste sentido, a presença dos aspectos relacionados à promoção da saúde, já que estes acompanham sempre os demais conceitos de SAN, fazendo interface com praticamente todos os itens dos PCN.
Na interface, é muito clara a intersecção dos temas relacionados à produção, mas ainda inconsistentes as questões relacionadas ao acesso aos alimentos. Do mesmo modo, a finalidade da alimentação nos seus diversos aspectos, o processo de nutrição, os hábitos alimentares, a obesidade, as carências nutricionais e a questão da água como recurso natural e necessário para o consumo 
humano, guardam pouca relação com os aspectos contemplados no conceito de SAN.

Com relação à análise da qualidade das informações e conceitos transmitidos segundo sua concordância com os conceitos científicos presentes em livros técnicos e publicações especializadas, não foi possível efetuá-la na íntegra. O material didático analisado apresenta Situações de Aprendizagem, mas não o conteúdo, sugerindo atividades a serem trabalhadas, sendo que os conteúdos deverão ser pesquisados pelo próprio professor e pelo aluno.

Estas Situações de Aprendizagem são problemas apresentados para discussão de temas com os estudantes. 0 currículo tem por finalidade desenvolver um conjunto de competências e habilidades específicas de compreensão e de reflexão crítica, relacionadas ao trabalho com o texto escrito. Para isto, é estimulada a leitura para a construção de um "repertório cultural específico" relacionado às diferentes áreas de conhecimento, exigindo a participação ativa do aluno. A estratégia educacional baseia-se na importância de levar o aluno a pensar e não apenas a reter informações.

Como exemplo, pode-se citar o seguinte:

Sétima série:

Tema discutido:

Ser humano: manutenção do organismo - Os nutrientes e suas funções no organismo, necessidades diárias de alimentos; dieta balanceada = alimenta ção variada.

Além do tema a ser discutido, são propostas ao docente, habilidades que deverão advir do tema discutido, como, por exemplo:
- Identificar diferentes necessidades nutricionais segundo idade, sexo e atividades diárias das pessoas;

- Identificar os principais tipos de nutrientes presentes nos alimentos mais comuns da dieta diária;

- Identificar e explicar as diferentes funções que os nutrientes têm no organismo.

Este e outros temas a serem trabalhados mostram que as responsabilidades no desenvolvimento das competências e habilidades dos alunos com relação aos aspectos relacionados à SAN cabem a professores de diferentes qualificações, sendo que muitas vezes o conhecimento requerido pelo docente pode ser mais ou menos próximo da sua área de formação. Outros exemplos que podem ilustrar esta afirmação são:

- "Meu bairro, minha comunidade" para a disciplina Inglês (6ª série);

- "Anúncios publicitários" para a disciplina Língua Portuguesa ( $7^{\underline{a}}$ série);

- "A tecnologia e os seres vivos: investigando as diferentes formas de conservação dos alimentos", para a disciplina Ciências (6ª série).

Para nortear o trabalho do docente, o material didático traz sugestões de estratégias de trabalho nas aulas, existindo sempre uma sondagem inicial para explorar os conhecimentos anteriores do aluno. Exemplos das estratégias propostas nos temas selecionados por este trabalho são apresentados no Quadro 3. Verifica-se a existência de estratégias a serem trabalhadas individualmente pelo aluno e também aquelas a serem trabalhadas pela sala como um todo.

\section{Quadro 3 - Sugestões de estratégias de trabalho do material didático da quinta à oitava séries do ensino fun- damental. São Paulo, 2009.}

\section{Individuais}

Leitura e interpretação de textos, tabelas, mapas, diagramas, gráficos;

Resolução de questionário;

Desenho;

Pesquisa orientada;

Coleta de dados;

Experimentos;

Produção de texto;

Construção de história em quadrinhos;

Construção de linha do tempo.

\section{Coletivas}

Trabalhos em grupo e exposição destes;

Discussões coletivas;

Construção coletiva de tabelas, gráficos;

Elaboração de esquema coletivo;

Aulas expositivas e dialogadas;

Observação de campo;

Discussões e debates em grupo;

Atividades práticas. 


\section{Discussão}

Verificou-se que os itens dispostos nos documentos analisados fazem interface com os itens que compõem o conceito de SAN. A utilização sustentável de recursos, a qualidade tecnológica e, em especial, a promoção da saúde, são os itens de SAN que mais se inter-relacionam com os PCNs.

0 exposto ratifica o reconhecimento da escola como ambiente propício à formação de hábitos saudáveis e à construção da cidadania, conforme disposto na Medida Provisória nำ1.010 de 08/05/2006 (Brasil, 20o6b) e na Lei nº 11.947 de 16/o6/2009 (Brasil, 2009).

Além disso, pesquisas têm apontado que estratégias educativas com crianças e adolescentes nas escolas melhoram os conhecimentos nutricionais, as atitudes e o comportamento alimentar, influenciando também os hábitos alimentares da família (Gabriel e col., 2008).

Destaca-se, aqui, a amplitude do conceito de Promoção da Saúde, já que este acompanha sempre os demais conceitos de SAN, fazendo interface com praticamente todos os itens dos PCNs. A Promoção da Saúde é um campo da Saúde Pública que se propõe a trabalhar com o conceito intersetorial e ampliado de saúde (Costa, 2008). Ela atua por meio da intervenção nos fatores sociais, econômicos e ambientais, a fim de melhorar as condições de vida e de saúde da população (Bydlowski e col., 2004).

O tema obesidade e carências nutricionais, no entanto, foi o único que não mostrou relação com a promoção da saúde, bem como com diversos outros aspectos componentes da SAN. É fundamental a abordagem do estado nutricional adequado de forma mais ampla, lembrando que algumas carências ainda persistem no Brasil (Coutinho e col., 20o8) e que o excesso de peso e a obesidade são encontrados com grande frequência, a partir dos 5 anos de idade, em todas as classes de renda e em todas as regiões, com tendência de aumento acelerado (IBGE, 2010).

A difusão da maioria das disciplinas por todos os bimestres no decorrer das quatro séries traz à tona uma discussão acerca da interdisciplinaridade em saúde. Este é um conceito considerado como "uma inter-relação e interação das disciplinas a fim de atingir um objetivo comum" (Meireles e Erdmann,
1999). A saúde é uma área interdisciplinar e demanda saberes das diferentes disciplinas para a construção de um olhar mais dinâmico e criativo sobre a alimentação como componente da saúde (Freitas e Penna, 2007). Um aspecto que merece destaque, no entanto, é a clara necessidade de preparo dos docentes para abordar conteúdos nem sempre correlatos à sua área de formação, como é o caso da discussão do bairro e da comunidade na disciplina de Inglês.

Os temas encontrados principalmente em Ciências, Geografia e História estão relacionados ao processo de construção histórica do conceito de SAN e correspondem a assuntos que vão desde questões sobre a terra e as crises econômicas até a globalização. O conceito inicial de SAN estava estritamente ligado à produção de alimentos e foi apenas a partir da década de 1980 que o acesso foi reconhecido como parte da Segurança Alimentar e Nutricional (Hirai e Anjos, 2007; Freitas e Saldiva, 2007). Atualmente existe a preocupação de garantir a distinção entre o conceito de acesso e o conceito de disponibilidade de alimentos, pois pode haver disponibilidade de alimentos sem que a população tenha acesso a eles devido a fatores como falta de renda, conflitos internos, ação de monopólios ou mesmo desvios (Belik, 2003). Nesse sentido, o tema alimentação e nutrição, desenvolvido na perspectiva SAN, perpassa também pela discussão do direito humano à alimentação adequada e a interface com a alimentação escolar. Adicionado a isso, o alimento - em especial aquele oferecido na escola - é parte do projeto pedagógico da escola, como determinam as novas diretrizes da alimentação escolar, disciplinada pela Lei $\mathrm{n}$ 11.947/2009 (Brasil, 2009). 0 acesso, portanto, está intimamente relacionado a temas como "caminho dos alimentos" e "formação de hábitos alimentares", que se mostram fundamentais, apesar de ainda incipientes, nestes documentos.

A utilização sustentável dos recursos, ou sustentabilidade, também é tratada com mais frequência nas disciplinas de Ciências, Geografia e História nos aspectos da produção, meio ambiente, poluição e desenvolvimento. Esta abordagem permite a reflexão sobre a importância de assegurar a produção, a distribuição e o consumo alimentar para gerações futuras (Maluf e col., 1996), incluindo temas como a utilização de agrotóxicos e a produção em monocul- 
turas (Belik, 2003). É observada a interface entre a produção de conhecimentos e acesso à informação e hábitos alimentares e necessidades socioculturais da alimentação. Destaca-se aqui a participação das disciplinas Educação Física e Inglês. A primeira abre um espaço chamado Aprendendo a Aprender, com temas sobre alimentação, e a segunda conta com um volume inteiro na sétima série com o tema Hábitos de alimentação. Apesar disto, estas disciplinas tiveram abordagem reduzida dos itens relacionados a SAN quando comparadas às demais disciplinas (Ciências, Geografia, História e Língua Portuguesa).

Com base na literatura, outros três conceitos podem ser abordados conjuntamente: as qualidades tecnológica, nutricional e biológica/sanitária. No material didático, a qualidade tecnológica é mais uma vez encontrada com maior frequência nas disciplinas de Ciências, História e Geografia, e praticamente ignorada na oitava série. A qualidade nutricional é abordada de forma mais clara e direta nas disciplinas de Ciências, Educação Física e Inglês. Por último, a qualidade biológica e sanitária é tratada dentro do tema saúde, principalmente na quinta e na sexta séries, com destaque à disciplina Ciências. A presença destes conceitos no material didático é importante, pois o acesso aos alimentos deve estar acompanhado pela boa qualidade nutricional, sanidade e isenção de componentes químicos prejudiciais à saúde humana (Maluf e col., 1996). A exposição crônica a produtos químicos em especial é muitas vezes responsável por diversas doenças, incluindo sintomas neurológicos infantis (Rovedatti e col., 2006).

As estratégias propostas no material didático, que oferece Situações de Aprendizagem sem apresentar os conteúdos, impossibilitaram a análise, neste estudo, da qualidade das informações e dos conceitos, mas conduzem à reflexão sobre a necessidade constante de atualização dos docentes responsáveis pelas suas respectivas disciplinas.

Sobre a capacitação de professores, Duarte (2004) relata que esta é apontada como pré-requisito fundamental para melhoria da qualidade do ensino, existindo estudos que afirmam sua importância no rendimento de aprendizagem dos alunos e a dificuldade em atingir a maioria dos profissionais. A Secre- taria de Educação do Estado de São Paulo promove, por meio do Programa São Paulo Faz Escola, um curso que visa à formação continuada de professores do ensino fundamental, denominado A Rede Aprende com a Rede, possibilitando a discussão a respeito do currículo com relação à prática em sala de aula e o material de apoio disponibilizado pelo Estado (São Paulo, 2008). Entretanto, este é um curso à distância em que o número de vagas é limitado, devendo o professor interessado inscrever-se, estando sua participação sujeita a critérios de seleção determinados para preenchimento das vagas, e pode não atender a todos. Estas e outras iniciativas são fundamentais para garantir a atualização de conteúdos

A busca destes conteúdos pelo professor pode gerar uma situação complexa, considerando a prática de cada professor. Fernandez e Silva (2008), em estudo sobre fontes de informação entre professores sobre alimentação e nutrição, evidenciou os livros de ciências naturais como a principal fonte de consulta; em $2^{\circ}$ lugar, os jornais e revistas de grande circulação; em $3^{\circ}$, as revistas de alimentação; e, em $4^{\circ}$, os programas de TV. Destaca-se que as posições $2^{a}$, $3^{\underline{a}}$ e $4^{\underline{a}}$ consistem em fontes não científicas de informação. Os profissionais de saúde apresentaram-se como a $5^{\text {a }}$ fonte de consulta, seguidos pelos manuais técnicos de alimentação (6 $6^{a}$ posição).

A diversidade de sugestões de estratégias para abordar o tema, tanto individual como coletivamente, demonstra a gama de possibilidades de desenvolvê-lo em sala de aula. Para Almeida (2002), existem dois tipos de ensino, um estritamente instrucional e um mobilizador "no sentido da descoberta, da atividade, dos conhecimentos anteriores e das capacidades dos alunos, sendo que este último apresenta vantagens na apreensão da informação". Neste sentido, segundo esse autor, estratégias, como as identificadas no material didático, deverão servir de subsídio ao docente.

Sobre a concepção de currículo, Moreira e Candau (2007) afirmam que:

Diferentes fatores socioeconômicos, políticos e culturais têm contribuído, assim, para que currículo seja entendido como: (a) os conteúdos a serem ensinados e aprendidos; (b) as experiências escolares de aprendizagem a serem vividas pelos 
alunos; (c) os planos pedagógicos elaborados por professores, escolas e sistemas educacionais; (d) os objetivos a serem alcançados por meio do processo de ensino; (e) os processos de avaliação que terminam por influir nos conteúdos e nos procedimentos selecionados nos diferentes graus da escolarização (p. 20).

Considerando que o material analisado contempla apenas os temas a serem estudados e as possibilidades de experiência de aprendizagem, mais informações seriam necessárias para analisar se o currículo dos estudantes das escolas públicas do Estado de São Paulo possibilitam realmente momentos de criação e revisão de hábitos e atitude. Entretanto, é possível identificar que os aspectos referentes à construção do conceito de SAN estão presentes no material didático.

Os princípios centrais da Proposta Curricular do Estado de São Paulo são: valorização do aprendizado pela escola, da cultura no currículo, da competência de leitura e de escrita e das competências para o mundo do trabalho (São Paulo, 2008). Sobre a escrita, Lima (2007) afirma que "escrever é uma aprendizagem, usar a escrita para aprender outras matérias é outra aprendizagem", sendo assim, o aluno que escreve organiza as informações recebidas por meio de relações entre elas e pode, com isso, sistematizar os conhecimentos de qualquer área do conhecimento. E essas possibilidades de aprender estão apresentadas como sugestões de estratégia de trabalho no material didático analisado.

\section{Conclusão}

Os temas referentes ao conceito de SAN são abordados no material didático de quinta a oitava séries do ensino fundamental, guardando interface com os PCNs. A análise mais detalhada mostrou que os referidos temas são discutidos em quase todas as disciplinas e com maior frequência da quinta a sétima séries, nas disciplinas de História, Geografia, Ciências e Língua Portuguesa, e menor frequência nas disciplinas de Inglês e Matemática. Na interface, é clara a presença dos aspectos relacionados à promoção da saúde e à produção dos alimentos, mas são inconsistentes outros importantes assuntos relacionados a SAN, tais como acesso e finalidade da alimentação nos seus diversos aspectos, ao processo de nutrição, aos hábitos alimentares, à obesidade, às carências nutricionais e à questão da água como recurso natural. Foram identificadas algumas estratégias, mas não foi possível analisar o conteúdo, dado que o material diz respeito a situações de aprendizagem, cabendo aos educadores a seleção adequada de conteúdo e da estratégia sugerida, e sua constante atualização, o que está sendo proposto pelo Estado, mas não está ao alcance de todos os profissionais e, portanto, ainda depende da iniciativa de cada docente, o qual deverá trabalhar conteúdo nem sempre correlato à sua área de formação.

\section{Referências}

ALMEIDA, L. S. Facilitar a aprendizagem: ajudar aos alunos a aprender e a pensar. Psicologia Escolar e Educacional, Campinas, v. 6, n. 2, p. 155165, dez. 2002.

BELIK, W. Perspectivas para segurança alimentar e nutricional no Brasil. Saúde e Sociedade, São Paulo, v. 12, n. 1, p. 12-20, jan./jun. 2003.

BRASIL. Decreto n. 591, de 6 de julho de 1992. Dispõe sobre o Pacto Internacional sobre Direitos Econômicos, Sociais e Culturais. Promulgação. Disponível em: <http://www.defensoria.sp.gov.br/ dpesp/Repositorio/31/Documentos/parcto\%20 internacional\%2osobre\%2odireitos\%20 econ $\%$ c3\%b4micos\%2osociais\%2oe\%2oculturais. pdf >. Acesso em: 10 out. 2010.

BRASIL. Ministério da Educação. Fundo Nacional do Desenvolvimento da Educação. Parâmetros Curriculares Nacionais : $3^{\circ}$ e $4^{\circ}$ ciclos do ensino Fundamental: saúde. Brasília, DF, 1998. Disponível em: <http://http://portal.mec.gov.br/ seb/arquivos/pdf/introducao.pdf $>$. Acesso em: 10 jun. 2010.

BRASIL. Lei ํㅡㄴ 11.346, de 15 de setembro de 2006a. Cria o Sistema Nacional de Segurança Alimentar e Nutricional - SISAN com vistas em assegurar o direito humano à alimentação adequada e dá outras providências. Diário Oficial da União, Brasília, DF, 18 de setembro de 2006. 
BRASIL. Portaria Interministerial MS/MEC n. 1.010, de o8 de maio de 2006b. Institui as diretrizes para a promoção da alimentação saudável nas escolas de educação infantil, fundamental e nível médio das redes públicas e privadas, em âmbito nacional. Diário Oficial da União, Brasília, DF, o9 maio 2006.

BRASIL. Lei n. 11.947, de 16 de junho de 2009. Dispõe sobre o atendimento da alimentação escolar e do Programa Dinheiro Direto na Escola aos alunos da educação básica; altera as leis n. 10.880, de 9 de junho de 2004, n. 11.273, de 6 de fevereiro de 2006, n. 11.507, de 20 de julho de 2007; revoga dispositivos da Medida Provisória n. 2.178-36, de 24 de agosto de 2001, e a Lei n. 8.913, de 12 de julho de 1994; e dá outras providências. Diário Oficial da União, Brasília, DF, 17 jun. 2009.

BRASIL. Constituição (1988). Emenda constitucional n. 64, de 05 de fevereiro de 2010a. Dá nova redação ao artigo 6 incluindo a alimentação como direito social. Brasília, DF: Senado, 2010.

BRASIL. Decreto n. 7.272, de 25 de agosto de 2010b. Regulamenta a Lei n. 11.346, de 15 de setembro de 2006. Dispõe a criação do Sistema Nacional de Segurança Alimentar e Nutricional SISAN com vistas a assegurar o direito humano à alimentação adequada, institui a Política Nacional de Segurança Alimentar e Nutricional - PNSAN, estabelece os parâmetros para a elaboração do Plano Nacional de Segurança Alimentar e Nutricional, e dá outras providências. Diário Oficial da União, Brasília, DF, 26 ago. 2010.

BURLANDY, L. Transferência condicionada de renda e segurança alimentar e nutricional. Revista Ciência \& Saúde Coletiva, Rio de Janeiro, v. 12, n. 6, p. 1441-1451, dez. 2007.

BYDLOWSKI, C. R.; WESTPHAL, M. F.; PEREIRA, I. M. T. B. Promoção da saúde: porque sim e porque ainda não! Saúde e Sociedade, São Paulo, v. 13, n. 1, p. 14-24, abr. 2004.

COSTA, C. G. A. Segurança alimentar e Nutricional - significados e apropriações. 2008. 306p. Dissertação (Mestrado em Saúde Pública) Faculdade de Saúde Pública, Universidade de São Paulo, São Paulo.
COUTINHO, J. G.; GENTIL, P. C.; TORAL

N. A. desnutrição e obesidade no Brasil: o enfrentamento com base na agenda única da nutrição. Cadernos de Saúde Pública, Rio de Janeiro, v. 24, Sup. 2, p. S332-S340, 2008.

DUARTE, V.C. Capacitação docente em Minas Gerais e São Paulo: uma análise comparativa. Cadernos de. Pesquisa, São Paulo, v. 34, n. 121, p. 139-168, abr. 2004.

FERNANDEZ, P. M.; SILVA, D. O. Descrição das noções conceituais sobre os grupos alimentares por professores de $1^{\underline{a}}$ a $4^{\underline{a}}$ série: a necessidade de

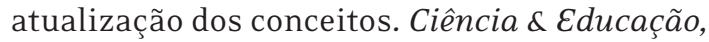
Bauru, v. 14, n. 3, p. 455-461, 2008.

FIATES, G. M. R.; AMBONI, R. D. M. C.; TEIXEIRA, E. Marketing, hábitos alimentares e estado nutricional: aspectos polêmicos quando o tema é o consumidor infantil. Alimentos e Nutricionistas, Araraquara, v. 17, n. 1, p. 105-112, jan./mar. 2006.

FREITAS, A. C; PENNA, C. L. Interdisciplinaridade. In: SANTOS, I. G. (Org.). Nutrição: da assistência à promoção da saúde. São Paulo: RCN Editora, 2007. p. 67-76.

FREITAS, A. C.; SALDIVA, S. R. D. M. A alimentação e a nutrição na saúde pública. In: SANTOS, I. G. (Org.). Nutrição: da assistência à promoção da saúde. São Paulo: RCN Editora, 2007. p. 35-53 GABRIEL, C. G.; SANTOS, M. V.; VASCONCELOS, F. A. G. Avaliação de um programa para promoção de hábitos alimentares saudáveis em escolares de Florianópolis, Santa Catarina, Brasil. Revista Brasileira de Saúde Materno Infantil, Recife, v. 8, n. 3, p. 299-308, 2008.

HIRAI, W. G; ANJOS, F. S. Estado e segurança alimentar: alcances e limitações de políticas públicas no Brasil. Revista Textos e Contextos, Porto Alegre, v. 6, n. 2, p. 335-353, jul./dez. 2007.

IBGE - Instituto Brasileiro de Geografia e Estatística. Pesquisa de orçamentos familiares 2008-2009: antropometria e estado nutricional de crianças, adolescentes e adultos no Brasil. Rio de Janeiro: IBGE, 2010. $130 \mathrm{p}$. 
LIMA, E. S. Currículo e desenvolvimento humano.

Boletim 17, Rio de Janeiro, p. 12-19, set. 2007.

Disponível em: <http://www.tvbrasil.org.br/fotos/ salto/series/155518Indagacoes.pdf >. Acesso em: 10 set. 2010 .

MALUF, R. S; MENEZES, F.; VALENTE, F. Contribuição ao tema da segurança alimentar no Brasil. Revista Cadernos de Debate (NEPA/ UNICAMP), Campinas, v. 4, p. 66-88, 1996.

MEIRELES, B. H. S.; ERDMANN, A. L. A questão das disciplinas e da interdisciplinaridade como processo educativo na área da saúde; Texto $\&$ Contexto Enfermagem, Florianópolis, v. 9, n. 1, p. 149-165, jan./abr. 1999.

MINISTÉRIO DA SAÚDE. Secretaria de Políticas de saúde. A promoção da saúde no contexto escolar. Revista de Saúde Pública, São Paulo, v. 36, n. 4, p. 533-535, 2002.

MOREIRA, A. F. B; CANDAU, V. M. Currículo, conhecimento e cultura. Boletim 17, Rio de Janeiro, p. 20-29, set. 2007. Disponível em: <http://www.tvbrasil.org.br/fotos/salto/ series/155518Indagacoes.pdf $>$. Acesso em: 10 nov. 2010.

ONU - Organização das Nações Unidas. Declaração Universal dos Direitos Humanos. Nova Iorque, 1948. Disponível em:_http://www.mj.gov.br/sedh/ ct/legis_intern/ddh_bib_inter_universal.htm>. Acesso em: o8 maio 2010.
PEDRINOLA, F. Nutrição e transtornos alimentares na adolescência. Revista Pediatria Moderna, São Paulo, v. 38, n. 8, p. 377-38o, ago. 2002.

PRIORE, S. E; FRANCESCHINI, S. C. C. Nutrição na Adolescência. In: SILVA, S. M. C. S.; MURA, S. D. P. Tratado da alimentação, nutrição e dietoterapia. São Paulo: Roca, 2007. p. 353-379.

ROVEDATTI, M. G. et al. Prevención en prevención en salud ambiental para poblaciones expuestas a plaguicidas: entrevistas en comunidades rurales y taller educativo para agentes multiplicadores. Acta Toxicológica Argentina, Buenos Aires, v. 14, n. 1, p. 2-7, 2006.

SANTOS, M. P. C. et al. Avaliação de políticas públicas de segurança alimentar e combate à fome no período 1995-2002. 4 - Programa Nacional de Alimentação Escolar. Cadernos de Saúde Pública, Rio de janeiro, v. 23, n. 11, p. 2881-2893, 2007.

SÃo PAULO. Secretaria de Estado da Educação. Proposta curricular do Estado de São Paulo. São Paulo, 2008. Disponível em: <http://www. rededosaber.sp.gov.br/portais/saopaulofazescola/ EnsinoFundCicloII/Materiais/tabid/1044/Default. aspx>. Acesso em: 21 nov. 2009.

VALENTE, F. L. S. Fome, desnutrição e cidadania: inclusão social e direitos humanos. Saúde e Sociedade, São Paulo, v. 12, n. 1, p. 51-6o, jun. 2003. 